BMJ Open Ophthalmology

\title{
Surgical management of intermittent exotropia: do we have an answer for all?
}

\author{
Pratik Chougule, Ramesh Kekunnaya
}

\begin{abstract}
To cite: Chougule $P$, Kekunnaya R. Surgical management of intermittent exotropia: do we have an answer for all? BMJ Open Ophthalmology 2019;4:e000243. doi:10.1136/ bmjophth-2018-000243
\end{abstract}

Received 28 0ctober 2018 Revised 20 December 2018 Accepted 28 December 2018

\section{Check for updates}

(C) Author(s) (or their employer(s)) 2019. Re-use permitted under CC BY-NC. No commercial re-use. See rights and permissions. Published by BMJ.

Child Sight Institute, Jasti V Ramanamma Children's Eye Care Centre, L V Prasad Eye Institute, Hyderabad, India

Correspondence to Dr Ramesh Kekunnaya; rameshak@lvpei.org

\section{ABSTRACT}

Intermittent exotropia $(X(T))$ is one of the most common form of strabismus with surgery being the mainstay of treatment. The main goal of surgery is to preserve binocular vision and stereopsis and to prevent its further loss. The decision to operate is mainly based on four aspects: increasing angle of exodeviation, deteriorating control of $X(T)$, decrease in stereopsis for near or distance and quality of life. Bilateral lateral rectus muscle recession and unilateral lateral rectus recession with medial rectus resection, are the two most common surgical procedures performed and have been studied extensively in basic, divergence excess and convergence insufficiency types of $X(T)$. However, there is no consensus over the relative efficacy of the two procedures in terms of postoperative alignment, residual or recurrent exotropia and consecutive esotropia with widely variable results, which can be attributed to poor understanding of the natural course of the disease. Multiple demographic, clinical and anatomic features that may influence the surgical outcomes have been studied to explain this variability. Moreover, most of the evidence regarding surgical outcomes of $X(T)$ is from retrospective studies and the ongoing randomised prospective trials can shed light on long-term efficacy of these procedures. The goal of this review is to give a comprehensive overview of the outcomes of various surgical techniques in the management of different types of $X(T)$, the preoperative and postoperative factors that may affect the surgical outcomes and to discuss the dilemmas faced by the treating surgeons including the effective management of overcorrection and undercorrection.

\section{INTRODUCTION}

Intermittent exotropia $(\mathrm{X}(\mathrm{T}))$ is one of the most common type of strabismus in children as well as adults, especially in the Asian and South Asian populations. ${ }^{1-4}$ In these populations, it has been estimated that the prevalence of exotropia can be up to 7-18.5 times higher than that of esotropia, out of which the most common type is $\mathrm{X}(\mathrm{T})$ accounting for about $63 \% .^{125}$ It is also one of the most common indications for strabismus surgery and its incidence is on the rise. ${ }^{36}$ This higher prevalence of exotropia in Asian population compared with West has been attributed to either ethnic differences or to the higher incidence of myopia in the Asian population. ${ }^{12}$

A wide variety of modalities have been described for the management of $\mathrm{X}(\mathrm{T})$ ranging from non-surgical to surgical. The goal of this review is to give a comprehensive overview of the relative outcomes of various surgical techniques in the management of different types of $\mathrm{X}(\mathrm{T})$, the preoperative and postoperative factors that may affect the surgical outcomes and to discuss the dilemmas faced by the treating surgeons.

\section{SURGICAL MODALITIES}

Spontaneous resolution of $\mathrm{X}(\mathrm{T})$ is $\operatorname{rare}^{7}$ and hence surgery has been the mainstay of the treatment of $\mathrm{X}(\mathrm{T})$.

\section{Indications of surgery}

The main goal of treatment in $\mathrm{X}(\mathrm{T})$ is to preserve the binocular vision and stereopsis and to prevent its further loss. The decision to operate is based on three major clinical aspects: increasing angle of exodeviation, deteriorating control of $\mathrm{X}(\mathrm{T})$ and decrease in stereopsis for near or distance. ${ }^{8}$ While the measurement of angle of deviation using alternate prism cover test and stereopsis using various modalities available is fairly reliable and objective, the measurement of control of $\mathrm{X}(\mathrm{T})$ is far more complex and subjective. Newcastle Control Score (NCS) is a simple tool devised to get reliable and easy to understand measurement of control by combining the assessment of control at home by guardians/parents and at office by the ophthalmologist to give a single numerical score with good interobserver and test-retest reliability. ${ }^{10}$ A similar office-only based scale by Mayo clinic measuring control for distance and near as a single numerical score has also shown good reliability, avoiding the recollection bias of home-based control assessment. ${ }^{11}$ Assigning a numerical value helps in serial monitoring of these patients for progression. Surgery is recommended if NCS $\geq 4$ or if it worsens over time, if $\mathrm{X}(\mathrm{T})$ is seen for greater than $50 \%$ of the awake time at home or if $\mathrm{X}(\mathrm{T})$ manifests spontaneously or with any form of fusion disruption without recovery. ${ }^{12}$

The most common non-clinical indication for surgery is to improve the quality of life. It has been shown that children are concerned 
about what others think of their appearance and strabismus can affect their ability to make friends, while parents worry more about the visual functions and the need for surgery. ${ }^{13-18}$ In such a situation, surgical correction may help in the psychosocial development of the individual, boosting their confidence and improving the way they interact with their peers and the society. It is important to understand that the decision of surgery cannot be taken based only on the above-mentioned parameters but is made depending on individual case. It is best to discuss with the individual and their parents/ guardians about the management options available and encourage them to actively participate in choosing the right approach for them.

\section{Basic X(T)}

Most commonly performed surgical procedures, unilateral lateral rectus recession and medial rectus resection (R\&R) and bilateral lateral rectus recession (BLRc), have been successfully performed for the management of basic type $\mathrm{X}(\mathrm{T}) .{ }^{19}$ Two randomised trials with one year follow-up have stated that R\&R results in better alignment and lower chances of recurrence of exotropia compared with BLRc, especially in the presence of ocular dominance. ${ }^{20}{ }^{21}$ However, R\&R resulted in a higher incidence of overcorrection, ${ }^{21}{ }^{22}$ which may induce diplopia or suppression and amblyopia. A recent meta-analysis concluded that R\&R resulted in better alignment, lower recurrence and similar overcorrection as that of BLRc, possibly be due to the leash effect of the resected medial rectus. The follow-up period in most studies was short. ${ }^{23}$ However, R\&R shows a greater exotropic drift after one year, with no significant difference between the two procedures over long term. ${ }^{1922} 24$ Moreover, it is difficult to compare between different studies directly due to significant differences in the study populations, variable surgical doses used, different definitions of successful outcomes and varied duration of follow-up. Therefore, it has been advocated to standardise the reporting of outcomes in future studies with respect to four aspects, namely angle of deviation, stereopsis, control and the quality of life. ${ }^{9}$ Considering these four key features, a recent well-conducted randomised trial comparing BLRc and R\&R, with 3 years postoperative follow-up, did not show any significant difference between the two types of surgeries ${ }^{25}$ On the contrary, multiple studies with longer follow-up suggest that BLRc has better long-term outcomes compared with R\&R, ${ }^{24} 26$ suggesting greater stability. Augmented surgical dosage for BLRc (aBLRc: augmenting the surgical dosage by $1-2.5 \mathrm{~mm}$ for each LR or increasing the target angle by 5 prism dioptres (PD) and R\&R (augmented R \& R = aR\&R: increasing the dosage of only MR resection by $1 \mathrm{~mm}$ ) improved long-term results compared with the original dosage with no significant difference in overcorrection ${ }^{28-31}$ (table 1 shows various surgical approach to different types of $\mathrm{X}(\mathrm{T})$ ).

\begin{tabular}{|c|c|}
\hline Indication for surgery & $\begin{array}{l}\text { 1. Poor/worsening of control } \\
\text { (Newcastle Control Score) } \\
\text { 2. Increasing angle of deviation } \\
\text { 3. Decrease in stereopsis for } \\
\text { distance or near } \\
\text { 4. Double vision } \\
\text { 5. Parental demand } \\
\text { 6. Quality of life }\end{array}$ \\
\hline Type of X(T) & Surgical procedure \\
\hline $\begin{array}{l}\text { 1. Basic or simulated } \\
\text { diveregence excess } \\
X(T)\end{array}$ & $\begin{array}{l}\text { 1. } B L R c \\
\text { 2. } U / L R \& R \\
\text { 3. } U / L L R c \\
\text { 4. Augmented } B L R c^{*}\end{array}$ \\
\hline $\begin{array}{l}\text { 2. Divergence excess } \\
X(T)\end{array}$ & $\begin{array}{l}\text { 1. BLRc } \\
\text { 2. Augmented BLRc } \\
\text { 3. BLRc +Faden suture (posterior } \\
\text { scleral fixation suture) to } B / L \\
\text { MR (for high } A C / A \text { ratio) } \\
\text { 4. BLRc + posterior pulley fixation } \\
\text { of } M R \text { (for high AC/A ratio) }\end{array}$ \\
\hline $\begin{array}{l}\text { 3. Convergence } \\
\text { insufficiency } X(T)\end{array}$ & $\begin{array}{l}\text { 1. U/L R\&R } \\
\text { 2. Augmented BLRc } \\
\text { 3. U/L or B/L MRs } \pm \text { slanting } \\
\text { (greater resection of lower } \\
\text { fibres of MR for near deviation } \\
\text { and lesser resection of } \\
\text { superior fibres) } \\
\text { 4. Improved R\&R-LRc for } \\
\text { distance and MRs for near } \\
\text { deviation } \\
\text { 5. Slanted BLRc-inferior pole } \\
\text { of insertion of LR is recessed } \\
\text { for near while the superior } \\
\text { pole is recessed for distance } \\
\text { deviation } \\
\text { 6. Augmented BLRc }\end{array}$ \\
\hline \multicolumn{2}{|l|}{ Resurgery† } \\
\hline $\begin{array}{l}\text { 1. Residual/recurrent } \\
\text { exotropia }\end{array}$ & $\begin{array}{l}\text { 1. } U / L \text { or } B / L \text { MRs (post-BLRc) } \\
\text { 2. LR recession of other eye } \\
\text { (post } U / L \text { surgery) } \\
\text { 3. LR rerecession (post small } \\
\text { LR recession, but less } \\
\text { predictable) }\end{array}$ \\
\hline $\begin{array}{l}\text { 2. Consecutive } \\
\text { esotropia }\end{array}$ & $\begin{array}{l}\text { 1. } U / L \text { or } B / L ~ M R c \\
\text { 2. } L R \text { advancement }\end{array}$ \\
\hline
\end{tabular}

*Augmented BLRc: increasing surgical dosage by $1.0-1.5 \mathrm{~mm}$ for BLRc.

†Preferably explore the previously operated muscle and look for stretched scar, slipped muscle, soft-tissue adhesions or other abnormalities in case of residual/recurrent exotropia or consecutive esotropia.

‡Dosage for LR advancement needs to be reduced due to greater effect per mm.

B/L, bilateral; BLRc, bilateral lateral rectus recession; LRc, lateral rectus recession; MRc, medial rectus recession; MRs, medial rectus resection; $R \& R$, unilateral lateral rectus recession with medial rectus resection; U/L, unilateral; $X(T)$, intermittent exotropia. 


\begin{tabular}{|c|c|c|}
\hline \multirow{2}{*}{$\begin{array}{l}\text { Exotropia angle in PD } \\
\text { Two muscles }\end{array}$} & \multicolumn{2}{|c|}{$\begin{array}{l}\text { Amount of recession/resection in } \\
\mathrm{mm}\end{array}$} \\
\hline & BLRc & LRc+MRs (R\&R) \\
\hline 15 & 4.0 & $4.0+3.0$ \\
\hline 20 & 5.0 & $5.0+4.0$ \\
\hline 25 & 6.0 & $6.0+4.0$ \\
\hline 30 & 7.0 & $7.0+5.5$ \\
\hline 35 & 7.5 & $7.5+5.5$ \\
\hline 40 & 8.0 & $8.0+5.5$ \\
\hline 45 & 8.5 & $8.5+6.0$ \\
\hline 50 & 9.0 & $9.0+6.5$ \\
\hline 60 & 10 & $9.0+7.0$ \\
\hline Three Muscles & \multicolumn{2}{|c|}{ BLRc+U/L MRs } \\
\hline 55 & \multicolumn{2}{|c|}{$8.0+5.0$} \\
\hline 60 & \multicolumn{2}{|c|}{$8.0+6.0$} \\
\hline 70 & \multicolumn{2}{|c|}{$9.0+6.0$} \\
\hline Four muscles & \multicolumn{2}{|c|}{ BLRc+BMRs } \\
\hline 75 & \multicolumn{2}{|c|}{$7.0+5.5$} \\
\hline 80 & \multicolumn{2}{|c|}{$7.0+6.0$} \\
\hline 90 & \multicolumn{2}{|c|}{$8.0+6.0$} \\
\hline
\end{tabular}

BLRc, bilateral lateral rectus muscle recession; BMRs, bilateral medial rectus resection; LRc, lateral rectus recession; MRs, medial rectus resection; $P D$, prism dioptres; $R \& R$, unilateral lateral rectus recession with medial rectus resection; $\mathrm{U} / \mathrm{L}$, unilateral.

Unilateral $\mathrm{R} \& \mathrm{R}$ is an asymmetrical procedure and there is a possibility of inducing lateral incomitance which is 10 times more compared with the symmetrical surgery in preoperative comitant strabismus. ${ }^{32-35}$ In a study by Graeber et al, $90 \%$ of patients having postoperative lateral incomitance had undergone asymmetrical surgery. ${ }^{32}$ While another study in children undergoing asymmetrical surgery, reported that $30 \%$ of cases with postoperative induced incomitance, had diplopia in side gazes, while $30 \%$ had concerns regarding their cosmetic appearance in side gazes even after 6 months. ${ }^{32}{ }^{35}$ On the contrary, unilateral surgery reduced the preoperative lateral incomitance in half of the cases. ${ }^{32}$ However, the evidence to show that unilateral surgery can induce lateral incomitance is scarce with only a couple of studies reporting the phenomenon, and more evidence is needed .

Small angle $\mathrm{X}(\mathrm{T})$ has been successfully managed by unilateral lateral rectus recession (ULRc), BLRc and $\mathrm{R} \& \mathrm{R},{ }^{36-38}$ but preoperative deviation of $20-25 \mathrm{PD} \mathrm{X}(\mathrm{T})$ had worse outcomes than $<20 \mathrm{PD} \mathrm{X}(\mathrm{T}) .{ }^{37}$ However, long-term results have been contradictory for ULRc with few studies showing good outcomes, ${ }^{36} 38$ while other showing poor outcomes compared with $\mathrm{R} \& \mathrm{R} .{ }^{40}$ Direct evidence comparison of BLRc and $R \& R$ for small angle $X(T)$ is scarce. Large angle $X(T)$ of $\geq 40$
PD showed significantly worse outcomes than moderate angle $\mathrm{X}(\mathrm{T})$ (20-30 PD), although no difference was found between BLRc and R\&R in either of the groups. ${ }^{41}$ However, large dose $R \& R$ may result in abduction limitation, lateral incomitance and palpebral fissure height narrowing or enophthalmos. ${ }^{42}$

The world is still divided over the choice of procedure for $\mathrm{X}(\mathrm{T})$ and is mostly based on individual surgeon's experience. ${ }^{22}$ However, in view of better long-term results, lower incidence of overcorrection thus reducing the threat of suppression and amblyopia as well as decreased chances of inducing lateral incomitance, the authors believe that BLRc may produce better and more acceptable results than $\mathrm{R} \& \mathrm{R}$ for the management of basic type of $\mathrm{X}(\mathrm{T})$. Perhaps, long-term outcomes of the ongoing randomised trials may reveal the relative efficacy of the two procedures in the management of $\mathrm{X}(\mathrm{T})$.

\section{Divergence excess}

Surgical outcomes in true divergence excess $\mathrm{X}(\mathrm{T})$ have been found to be better than basic X(T) ${ }^{22}$ with BLRc has been preferred over $R \& R$ for divergence excess type of $\mathrm{X}(\mathrm{T})$ due to greater chances of overcorrection following $R \& R .{ }^{22}$ Distance deviation after prolonged occlusion test has been considered as the target angle for surgical correction. ${ }^{43}$ aBLRc has been reported to give better long-term outcomes in divergence excess type of $\mathrm{X}(\mathrm{T})$ with success rates close to $80 \%$ without any significant increase in overcorrection for distance as well as near ${ }^{28} 434$ while stereopsis improved in half of these cases. ${ }^{43}$ These children have better near fusional capacity which may result in better fusional lock postoperatively leading to better stability of the angle. ${ }^{22} 28$ In case of high AC/A ratio, bifocals for decreased near accommodation can be prescribed or faden procedure formedial rectus (MR) can be added to BLRc in order to prevent postoperative overcorrection for near. ${ }^{45} \mathrm{~A}$ new surgical procedure of posterior pulley fixation of MR along with BLRc has been described in similar cases with good outcomes, ${ }^{46}$ with theoretically lesser chances of scleral perforation. In summary, BLRc resulting in lesser overcorrection has been preferred over R\&R with $^{22}$ good surgical outcomes compared with basic $\mathrm{X}(\mathrm{T})$.

\section{Convergence insufficiency}

A trial of non-surgical management like fusional and convergence exercises should be administered before surgical correction. It is common practice to add MR resection for treating convergence insufficiency and there is poor evidence for direct comparison of BLRc and R\&R in these cases. Most authors have suggested an improved R \& R (iR\&R) higher dose of MR resection based on near deviation compared with a lower dose of LR recession based on distance deviation.$^{47} 48$ Apart from the conventional R\&R procedure, several methods like unilateral ${ }^{49}$ or bilateral medial rectus resection with or without slanting (greater resection 
of lower fibres of MR for near deviation and lesser resection of superior fibres), ${ }^{50} 51$ improved $R \& R^{47}$ have been described for convergence insufficiency $\mathrm{X}(\mathrm{T})$ with variable success rates. Most patients have poor outcomes, which has led to the need to develop such diverse surgical procedures. iR\&R showed better results compared with unilateral and bilateral MR resection. ${ }^{52}$ Various modifications of BLRc such as adjustable sutures, aBLRc and slanted BLRc (sBLRc) have shown satisfactory outcomes. ${ }^{5354}$ sBLRc has shown better results compared with conventional BLRc and other procedures with $1 \mathrm{~mm}$ of slant reducing the near-distance disparity by 4.6-8.7 PD and lower rates of immediate postoperative overcorrection. ${ }^{55}{ }^{56}$ However, long-term outcomes of this procedures are not available. A recent prospective study comparing three procedures iR\&R (in non-dominant eye), sBLRc and aBLRc (in patients with no ocular dominance) showed a similar improvement for near deviation. ${ }^{53}$ However, sBLRc showed slightly better distance deviation outcomes compared with the other two procedures. aBLRc and sBLRc achieved better collapse of near-distance disparity compared with iR\&R. ${ }^{53}$ Each procedure had their own set of adverse events. Overcorrection was reported in $27 \%$ of aBLRc cases at 1 year, especially for distance, iR\&R had significantly higher undercorrection rate for distance compared with other groups while sBLRc induced asymptomatic pattern strabismus in approximately one in five cases ${ }^{53}$ Although sBLRc achieved significantly better alignment compared with the other two groups with lowest rates of over or undercorrection, long-term outcomes of this procedure are yet to be reported. To conclude, management of convergence insufficiency is still challenging with no particular surgical procedure being superior to the other. However, most surgeons prefer to include at least one $\mathrm{R} \& \mathrm{R}$ in their surgical plan.

\section{FACTORS AFFECTING SURGICAL OUTCOMES}

Surgical outcomes in $\mathrm{X}(\mathrm{T})$ have been quite variable with various studies reporting quite different rates of success and this can be attributed to the poor understanding of the natural course of the disease. The influence of various demographic, clinical and anatomic features on these outcomes is still debatable. The association of the following factors with that of surgical outcomes in $\mathrm{X}(\mathrm{T})$ has been studied.

\section{Age}

It has long been debated over timing of surgery with some advocating an early surgery before 4 years of age but was associated with a higher incidence of amblyopia due to the mild overcorrection in the postoperative period in these children with immature visual system. ${ }^{57}$ Interestingly, binocular visual integration pathway in these cases is intact, unlike infantile esotropia which warrants early intervention. The exotropia being intermittent, allows for development of binocular fusion and stereopsis. ${ }^{58} 59$ Therefore, delaying the surgery should not influence the sensory and visual outcomes to a great extent, ${ }^{60} 61$ and many studies have advocated for a delayed approach as it may also allow for more accurate measurements and better results, ${ }^{5862}{ }^{63}$ However, multiple reports have suggested that best results are achieved if operated before the age of 7 years of age ${ }^{64-66}$ due to a greater chance of postoperative bifoveal fusion with superior binocular vision and stereoacuity. Other possible explanation could be the structural changes in the periocular tissue due to longer duration of $\mathrm{X}(\mathrm{T})$ changing the elastic forces affecting the final postoperative correction. Age also affects the surgical dose-effect response, with postoperative change in deviation being highest in children $<7$ years age, followed by $7-12$ age group and least in children $>12$ years age, in children undergoing BLRc. ${ }^{67}$ Reducing the surgical dose by 1 $\mathrm{mm}$ in children $<7$ years age did not change the overall surgical outcomes but decreased the chances of overcorrection, while increasing the surgical dosage by 1.5 $\mathrm{mm}$ for children $>12$ years age significantly improved the surgical outcomes. ${ }^{67}$ This could be due to narrower tendons in children $<5$ years age resulting in greater effect of recession and changes in the periocular tissue in long-standing exotropia in older children, requiring augmented dosage to overcome their elastic forces. ${ }^{6768}$ In the authors' opinion, best outcomes are obtained between 4 and 7 years of age allowing for more accurate preoperative evaluation, reducing the chances of postoperative suppression and amblyopia and good motor alignment (except in case of large angle of exotropia with poor or worsening control and stereopsis, in which case an early surgery is indicated).

\section{Stereopsis, binocular vision, amblyopia}

Distance stereopsis is affected earlier in $\mathrm{X}(\mathrm{T})$ compared with near stereopsis. ${ }^{69}$ Some investigators advocate the use of distance stereoacuity to monitor the progression of distance, indication for surgery and as an outcome measure. ${ }^{69-73}$ It is intuitive to consider that better stereopsis must be associated with good control of $\mathrm{X}(\mathrm{T})$ and smaller angle of deviation. However, $\mathrm{X}(\mathrm{T})$ patients can have any possible combination of stereopsis, control and angle of deviation with weak or no correlation between these factors. ${ }^{74}$ Similarly, stereopsis or binocular vision has not been found to affect the surgical motor outcomes. ${ }^{66} 75-77$ Such poor correlation may result from variable measurements of stereopsis and angle of deviation in $\mathrm{X}(\mathrm{T})$ specially in younger children. ${ }^{78-81}$ However, a recent study showed that loss of stereopsis was the only feature associated with poor outcomes on multivariate analysis ${ }^{82}$ which may suggest that if any such association does exist, it may either be affected by multiple factors or too weak to be consistent. On the contrary, surgical correction does improve stereopsis significantly even in the long term. ${ }^{25} 83$ Amblyopia is not common in these patients, if present is not severe ${ }^{784}$ but needs exploration 
for other causes like anisometropia and does not significantly affect the surgical outcomes. ${ }^{6675}$

\section{Refractive error}

It has been recommended to overcorrect myopia slightly to induce convergence for better control of $\mathrm{X}(\mathrm{T})$ as a temporary measure. In case of significant myopia of $\geq-5 \mathrm{D}$, it is advisable to reduce the surgical dosages accordingly. ${ }^{85-87}$ Although the effect of axial length on surgical outcomes is debatable, a recent study has shown negative correlation of axial length with mean dose response. ${ }^{88}$ Most studies have shown that refractive error or anisometropia does not affect the final surgical outcomes. ${ }^{586367}$ Some studies have shown that myopia has less favourable response to surgery, ${ }^{77}$ while others have shown a favourable outcome.$^{76}$ Anisometropia has also been reported to be associated with poor outcomes. ${ }^{89}$

\section{Preoperative angle of deviation}

Few studies have suggested that preoperative deviation less than 40 PD does not affect the final surgical outcomes ${ }^{5863}$ while greater preoperative deviation especially if $>40 \mathrm{PD}$ is associated with poor outcomes. ${ }^{66767790}$ In authors' opinion, preoperative exodeviations lying within the grey zone which pose the dilemma of whether to add an extra muscle like 20-25 PD (1 or 2 muscles), 45-55 PD (2 or 3 muscles) and 60-90 PD (3 or 4 muscles) have unpredictable outcomes, with most unpredictable outcomes in the first group of 20-25 PD. ${ }^{37}$ The surgical dosage for $\mathrm{X}(\mathrm{T})$ has been discussed in table 2. Variability in the measurement of exotropia (7.2 PD for distance and 12.8 for near for moderate angle deviation) may also affect the outcomes of surgery. ${ }^{80}$ Different surgical dosages are used for same amount of deviation which can potentially explain the wide variability of the outcomes reported in literature, however, no such relation was found in a study by Chia et $a .^{22}$ Another potential cause for inconsistent surgical outcomes could be not operating for the maximum angle of deviation. ${ }^{91}$ Suggestions have been made to consider largest measured angle as the target angle for surgery for good outcomes, not necessarily the measurement of $\mathrm{X}(\mathrm{T})$ with a distant outdoor fixation target, ${ }^{92}$ without an increase in overcorrection.

\section{Control}

Preoperative control does not affect final surgical outcomes. ${ }^{22}$ The poor association of control, stereopsis and angle of deviation and their complex interactions in maintaining alignment, may be responsible for poor association between these factors and surgical outcomes. Most studies including the randomised trial have reported an improvement in control following surgery. ${ }^{25} 93$

\section{Early postoperative angle}

Postoperative exodrift is common, hence, a target angle of small esotropia $(\leq 10 \mathrm{PD})$ is desirable in the immediate postoperative period, ${ }^{94-96}$ but it does not guarantee a successful outcome. ${ }^{97} 98$ Some studies suggest that initial overcorrection up to 17-20 PD is acceptable ${ }^{609499}$ but an overcorrection of $\geq 10$ PD has higher chances of consecutive esotropia. ${ }^{96}$ Concerns have been raised regarding the development of consecutive esotropia and monofixation syndrome due to overcorrection, especially in young children. ${ }^{97}$ On the contrary, residual exotropia at immediate, one week and onemonth postoperative period is usually associated with higher recurrence rates. ${ }^{586366}$

\section{Follow-up period}

It has been reported that the most important factor determining surgical outcomes based on alignment is the duration of follow-up, with half the surgeries failing after 5 years which increases to $76 \%$ at 10 years and $86 \%$ failing after 15 years. ${ }^{83}$ A total of $20 \%-60 \%$ patients require a second surgery at mean follow-up of 10 years, most of them for a recurrence of exotropia. ${ }^{83} 89$ Another study using more robust criteria for surgical success including motor alignment, stereopsis and control with at least 5-year follow-up, found successful cure in only $30 \%$ of patients undergoing surgery. ${ }^{93}$ Although surgery improved the distance and near deviation significantly compared with those who were observed conservatively, no significant difference was found in the final number of patients without tropia (considered as cured) and its control between the two groups after 5 years follow-up, raising the question 'Is X(T) a curable condition?'. ${ }^{93}$ Although stereopsis improves following surgery, patients undergoing surgery had poorer final stereopsis compared with those managed conservatively, ${ }^{93}$ which may be due to the desired small target microtropia in the postoperative period or poorer preoperative stereopsis to begin with in this group. The natural course of $\mathrm{X}(\mathrm{T})$ does not show significant deterioration of angle of deviation, control or stereopsis in untreated cases. $^{84}{ }^{100}$ Considering the poor long-term surgical motor outcomes and the association of better stereopsis with conservative management, the advantage of reducing the angle of deviation and improving the quality of life in these patients by operating should be weighed cautiously in the presence good preoperative binocular vision and stereopsis especially in small angle $\mathrm{X}(\mathrm{T})$ cases.

\section{Lateral incomitance}

Few investigators found lateral incomitance to be a significant risk factor for development of consecutive esotropia, ${ }^{89} 101102$ while others did not. ${ }^{34}$ Asymmetrical surgery may induce lateral incomitance postoperatively but it may also be indicated to reduce preoperative lateral incomitance if planned appropriately. ${ }^{32} 35$

\section{Vertical strabismus}

Primary oblique muscle overaction $(7 \%-25 \%)$, dissociated vertical deviation (DVD) $(5 \%-8 \%)$ and vertical 
deviation (24\%) although poorly studied are not uncommon in $\mathrm{X}(\mathrm{T}) .{ }^{4182} \mathrm{DVD}$ in $\mathrm{X}(\mathrm{T})$ is smaller than in infantile esotropia and is associated with poorer stereopsis. ${ }^{103}$ If these anomalies are mild, horizontal muscle surgery may resolve vertical deviation and oblique muscle overaction. ${ }^{82} 104{ }^{105}$ Vertical offset of horizontal muscles or vertical muscle surgery is indicated if the vertical deviation or DVD is $\geq 10-14 \mathrm{PD}$, DVD is manifest quite often, significant pattern deviation and oblique overaction of $\geq+2 .{ }^{82} 106$ DVD, vertical deviation and primary oblique muscle overaction did not significantly affect surgical outcomes. ${ }^{82}$

\section{Anatomic factors}

Greater the LR insertion to limbus distance, greater is the surgical effect for a fixed amount of recession with twice the effect in BLRc compared with unilateral LR recession. ${ }^{107}$ Similarly, the effect of recession is larger in narrower LR tendon width. ${ }^{108}$ Although the role of anatomical factors in the natural history of $\mathrm{X}(\mathrm{T})$ and its surgical outcomes is poorly understood, multiple structural changes are seen in long-standing cases in the extraocular muscle including its myofilaments and sarcomeres, axonal supply, proprioception apparatus and the surrounding extracellular matrix and collagen. ${ }^{109-111}$ Early surgical intervention may prevent the progression of these changes. ${ }^{111}$

\section{MANAGEMENT OF SURGICAL UNDER OR OVERCORRECTIONS}

(Table 1) A large overcorrection or undercorrection in immediate postoperative period with limitation of motility suggests a slipped muscle and should be operated immediately. If the motility is good, chances of spontaneous recovery are higher, ${ }^{97112113}$ and managed conservatively with monocular patching \pm Fresnel prisms. If the esodeviation does not decrease for more than 9-12 months, chances of spontaneous resolution are slim, however, late spontaneous resolutions have been reported. ${ }^{112}{ }^{113}$ Surgical correction may be considered in such cases based on 'Cooper's dictum' which states that if there is no limitation of motility, surgery should be performed on unoperated muscles as if it was the initial operation, however, if there is motility limitation, surgery should be performed on previously operated muscles ${ }^{114}$ In long term, residual exotropia is far more common than consecutive esotropia, since an exodrift is commonly seen in the postoperative period. ${ }^{8389}$ Medial rectus resection (MRs) is recommended for residual exotropia after BLRc if motility is good. Unilateral MRs shows good outcomes for moderate exodeviations $(\leq 25 \mathrm{PD})^{115-117}$ with one study suggesting similar outcomes while another reporting lower overcorrection compared with that of bilateral MRs. The amount of resection in case of bilateral MRs should be reduced as the lateral rectus has already been recessed. ${ }^{117} 118$ Residual/recurrent exotropia following unilateral $\mathrm{R} \& \mathrm{R}$ procedure can be managed with LR recession with or without MRs of the other eye. In case of consecutive esotropia with or without limited abduction following LR recession, surgical exploration for stretched scar and its repair, if present, is needed with or without MR recession or LR advancement. In case of normal motility MR recession with or without LR resection of the unoperated muscles is more predictable. LR advancement has been tried in patients with no motility limitation and produces a far greater effect per mm compared with the same dose of LR recession for treating exotropia. ${ }^{119}$ Hence, the dose of LR advancement should be reduced with Kim and Lee. suggesting to consider one fourth of the angle of esodeviation as the target angle and apply the doses of LR recession for same angle of exodeviation. ${ }^{120}$ This could be due to decreased elasticity of the previously recessed LR, hence its advancement may lead to a leash effect. ${ }^{120}$

\section{SUMMARY}

Best success rates are achieved in divergence excess type of $\mathrm{X}(\mathrm{T})^{22}$ while convergence insufficiency results in worst outcomes. $\mathrm{R} \& \mathrm{R}$ produces better outcomes than BLRc at one year postoperatively, although most studies did not find any significant difference in long term. Since, most of the evidence regarding surgical outcomes of $\mathrm{X}(\mathrm{T})$ is from retrospective studies, ongoing randomised prospective trials comparing BLRc and $\mathrm{R} \& \mathrm{R}$ will shed light on the long-term stability of the two procedures. The debate over the preferred surgical procedure still continues and mainly depends on the surgeons experience. ${ }^{22}$ Surgical management of $\mathrm{X}(\mathrm{T})$ is far from perfect due to variable results. Various preoperative and postoperative factors that may influence the outcomes have been studied to explain this variability, although none has been found to have a strong association with the outcomes. Even the surgical dosages used by the surgeons across the world vary which may explain the variability of the reported success rates to some extent. Future studies should further examine these predictive factors to tailor the surgical choice and dosage for optimal results. In addition, there are lot of lacunae in understanding the aetiopathogenesis and natural course of the disease itself which needs further exploration.

Contributors PC and RK planned the study, PC did the literature search, PC and RK drafted the manuscript along with its revisions, PC and RK prepared the tables.

The authors have not declared a specific grant for this research from any funding agency in the public, commercial or not-for-profit sectors.

Competing interests None declared.

Patient consent Not required.

Provenance and peer review Not commissioned; externally peer reviewed.

Open access This is an open access article distributed in accordance with the Creative Commons Attribution Non Commercial (CC BY-NC 4.0) license, which permits others to distribute, remix, adapt, build upon this work non-commercially, and license their derivative works on different terms, provided the original work is properly cited, appropriate credit is given, any changes made indicated, and the use is non-commercial. See: http://creativecommons.org/licenses/by-nc/4.0/. 


\section{REFERENCES}

1. Chia A, Dirani M, Chan Y-H, et al. Prevalence of amblyopia and strabismus in young singaporean Chinese children. Invest Ophthalmol Vis Sci 2010;51:3411-7.

2. Bruce A, Santorelli G. Prevalence and risk factors of strabismus in a UK multi-ethnic birth cohort. Strabismus 2016;24:153-60.

3. CBO Y, DSP F, Wong VWY, et al. Changing patterns of strabismus: a decade of experience in Hong Kong. $\mathrm{Br} \mathrm{J}$ Ophthalmol 2002;86:854-6.

4. Mohney BG, Huffaker RK. Common forms of childhood exotropia. Ophthalmology 2003;110:2093-6.

5. Goseki T, Ishikawa $\mathrm{H}$. The prevalence and types of strabismus, and average of stereopsis in Japanese adults. Jpn J Ophthalmol 2017;61:280-5.

6. Jie $\mathrm{Y}, \mathrm{Xu} \mathrm{Z}, \mathrm{He} \mathrm{Y}$, et al. A 4 year retrospective survey of strabismus surgery in Tongren Eye Centre Beijing. Ophthalmic Physiol Opt 2010;30:310-4.

7. Nusz KJ, Mohney BG, Diehl NN. The course of intermittent exotropia in a population-based cohort. Ophthalmology 2006;113:1154-8.

8. Hatt SR, Gnanaraj L, Cochrane Eyes and Vision Group. Interventions for intermittent exotropia. Cochrane Database Syst Rev 2013;116.

9. Chiu AKC, Din N, Ali N. Standardising reported outcomes of surgery for intermittent exotropia - a systematic literature review. Strabismus 2014;22:32-6.

10. Haggerty $\mathrm{H}$, Richardson $\mathrm{S}$, Hrisos $\mathrm{S}$, et al. The Newcastle control score: a new method of grading the severity of intermittent distance exotropia. Br J Ophthalmol 2004;88:233-5.

11. Mohney BG, Holmes JM. An office-based scale for assessing control in intermittent exotropia. Strabismus 2006;14:147-50.

12. Buck D, Hatt SR, Haggerty $\mathrm{H}$, et al. The use of the Newcastle control score in the management of intermittent exotropia. $\mathrm{Br} J$ Ophthalmol 2007;91:215-8.

13. Sim B, Yap GH, Chia A. Functional and psychosocial impact of strabismus on Singaporean children. J Aapos 2014;18:178-82.

14. Hatt SR, Leske DA, Liebermann L, et al. Associations between health-related quality of life and the decision to perform surgery for childhood intermittent exotropia. Ophthalmology 2014;121:883-8.

15. Hatt SR, Leske DA, Holmes JM. Comparison of quality-oflife instruments in childhood intermittent exotropia. $J$ Aapos 2010;14:221-6.

16. Mojon-Azzi SM, Kunz A, Mojon DS. Strabismus and discrimination in children: are children with strabismus invited to fewer birthday parties? Br J Ophthalmol 2011;95:473-6.

17. Paysse EA, Steele EA, McCreery KM, et al. Age of the emergence of negative attitudes toward strabismus. J Aapos 2001;5:361-6.

18. Satterfield D, Keltner JL, Morrison TL. Psychosocial aspects of strabismus study. Arch Ophthalmol 1993;111:1100-5.

19. Yuksel D, Spiritus M, Vandelannoitte S. [Symmetric or asymmetric surgery for basic intermittent exotropia]. Bull Soc Belge Ophtalmol 1998;268:195-9.

20. Kushner BJ. Selective surgery for intermittent exotropia based on distance/near differences. Arch Ophthalmol 1998;116:324-8.

21. Jeoung JW, Lee MJ, Hwang JM. Bilateral lateral rectus recession versus unilateral recess-resect procedure for exotropia with a dominant eye. Am J Ophthalmol 2006;141:683-8.

22. Chia A, Seenyen L, Long QB. Surgical experiences with twomuscle surgery for the treatment of intermittent exotropia. J Aapos 2006;10:206-11.

23. Sun Y, Zhang T, Chen J. Bilateral lateral rectus recession versus unilateral recession resection for basic intermittent exotropia: a meta-analysis. Graefes Arch Clin Exp Ophthalmol 2018;256:451-8.

24. Choi J, Chang JW, Kim SJ, et al. The long-term survival analysis of bilateral lateral rectus recession versus unilatera recession-resection for intermittent exotropia. Am J Ophthalmol 2012;153:343-51.

25. Donahue SP, Chandler DL, Holmes JM, et al. A randomized trial comparing Bilateral lateral rectus recession versus unilateral recess and Resect for Basic-Type intermittent exotropia. Ophthalmology 2018;0.

26. Maruo T, Kubota N, Sakaue T, et al. Intermittent exotropia surgery in children: long term outcome regarding changes in binocular alignment. A study of 666 cases. Binocul Vis Strabismus $Q$ 2001;16:265-70.

27. Yang X, Man TT, Tian QX, et al. Long-term postoperative outcomes of bilateral lateral rectus recession vs unilateral recession-resection for intermittent exotropia. Int J Ophthalmol 2014;7:1043-7.

28. Kim H, Yang HK, Hwang JM. Long-term surgical outcomes of augmented Bilateral lateral rectus recession in children with intermittent exotropia. Am J Ophthalmol 2016;163:11-17.
29. Lee SY, Hyun Kim J, Thacker NM. Augmented Bilateral lateral rectus recessions in basic intermittent exotropia. J Aapos 2007;11:266-8.

30. Arda H, Atalay HT, Orge FH. Augmented surgical amounts for intermittent exotropia to prevent recurrence. Indian J Ophthalmol 2014;62:1056-9.

31. Kim J-S, Yang HK, Hwang J-M. Long-term outcomes of augmented unilateral recess-resect procedure in children with intermittent exotropia. Plos One 2017;12:e0184863.

32. Graeber CP, Hunter DG. Changes in lateral Comitance after asymmetric horizontal strabismus surgery. JAMA Ophthalmol 2015;133:1241-6.

33. Tibrewal S, Singh N, Ganesh S. Unilateral strabismus surgery in patients with exotropia results in postoperative lateral incomitance. $J$ Aapos 2015;19:293-4.

34. Yoon $\mathrm{CH}$, Kim S-J. Lateral incomitancy and surgical results in intermittent exotropia. Br J Ophthalmol 2014;98:1404-8.

35. Deacon BS, Fray KJ, Grigorian AP, et al. Unilateral strabismus surgery in patients with exotropia results in postoperative lateral incomitance. J Aapos 2014:18:572-5.

36. Menon V, Singla MA, Saxena R, et al. Comparative study of unilateral and bilateral surgery in moderate exotropia. $J$ Pediatr Ophthalmol Strabismus 2010;47:288-91.

37. Lyu IJ, Park K-A, Oh SY. Long-term surgical outcomes and factors for recurrence after unilateral lateral rectus muscle recession. $\mathrm{Br} \mathrm{J}$ Ophthalmol 2016;100:1433-6.

38. Kim HJ, Kim D, Choi DG. Long-term outcomes of unilateral lateral rectus recession versus recess-resect for intermittent exotropia of 20-25 prism diopters. BMC Ophthalmol 2014;14:46.

39. Suh SY, Choi J, Kim SJ. Comparative study of lateral rectus recession versus recession-resection in unilateral surgery fo intermittent exotropia. J Aapos 2015;19:507-11.

40. Kim H, Yang HK, Hwang JM. Comparison of long-term surgical outcomes between unilateral recession and unilateral Recession-Resection in small-angle exotropia. Am J Ophthalmol 2016;166:141-8.

41. Jin KW, Choi DG. Outcome of two-muscle surgery for largeangle intermittent exotropia in children. $\mathrm{Br} J$ Ophthalmol 2017;101:462-6.

42. Parks MM PJ. Atlas of strabismus surgery. Philadelphia: Harper \& Row, 1983.

43. Magli A, Esposito Veneruso P, Chiariello Vecchio E, et al. Divergence excess intermittent exotropia: long-term effect of augmented Bilateral lateral rectus recession. Semin Ophthalmol 2018;33:512-6.

44. Çelebi S, Kükner AS. Large Bilateral lateral rectus recession in large angle divergence excess exotropia. Eur J Ophthalmol 2001;11:6-8.

45. Brodsky MC, Fray KJ. Surgical management of intermittent exotropia with high Ac/A ratio. J Aapos 1998;2:330-2.

46. Choi HY, Jung JH. Bilateral lateral rectus muscle recession with medial rectus pulley fixation for divergence excess intermittent exotropia with high Ac/A ratio. J Aapos 2013;17:266-8.

47. Kraft SP, Levin AV, Enzenauer RW. Unilateral surgery for exotropia with convergence weakness. J Pediatr Ophthalmol Strabismus 1995;32:183-7.

48. Choi MY, Hyung S-M, Hwang J-M. Unilateral recession-resection in children with exotropia of the convergence insufficiency type. Eye 2007;21:344-7.

49. de Decker W, Baenge JJ. Unilateral medial rectus resection in the treatment of small-angle exodeviation. Graefe's Arch Clin Exp Ophthalmol 1988;226:161-4

50. von Noorden GK. Resection of both medial rectus muscles in organic convergence insufficiency. Am J Ophthalmo 1976;81:223-6.

51. Hermann JS. Surgical therapy of convergence insufficiency. $J$ Pediatr Ophthalmol Strabismus 1981;18:28-31.

52. Wang $B$, Wang $L$, Wang $Q$, et al. Comparison of different surgery procedures for convergence insufficiency-type intermittent exotropia in children. Br J Ophthalmol 2014;98:1409-13.

53. Farid MF, Abdelbaset EA. Surgical outcomes of three different surgical techniques for treatment of convergence insufficiency intermittent exotropia. Eye 2018;32:693-700.

54. Ma L, Yang L, Li N. Bilateral lateral rectus muscle recession for the convergence insufficiency type of intermittent exotropia. J Aapos 2016;20:194-6.

55. Snir M, Axer-Siegel R, Shalev B, et al. Slanted lateral rectus recession for exotropia with convergence weakness. Ophthalmology 1999;106:992-6.

56. Chun BY, Kang KM. Early results of slanted recession of the lateral rectus muscle for intermittent exotropia with convergence insufficiency. J Ophthalmol 2015;2015:1-5. 
57. Pratt-Johnson JA, Barlow JM, Tillson G. Early surgery in intermittent exotropia. Am J Ophthalmol 1977;84:689-94.

58. Lim SH, Hwang BS, Kim MM. Prognostic factors for recurrence after bilateral rectus recession procedure in patients with intermittent exotropia. Eye 2012;26:846-52.

59. Burke MJ. Intermittent exotropia. Int Ophthalmol Clin 1985;25:53-68

60. Richard JM, Parks MM. Intermittent exotropia. surgical results in different age groups. Ophthalmology 1983;90:1172-7.

61. Stoller SH, Simon JW, Lininger LL. Bilateral lateral rectus recession for exotropia: a survival analysis. J Pediatr Ophthalmol Strabismus 1994;31:89-92

62. Edelman PM, Brown MH, Murphree AL, et al. Consecutive Esodeviation ... then what? Am Orthopt J 1988;38:111-6.

63. Lim SH, Hong JS, Kim MM. Prognostic factors for recurrence with unilateral recess-resect procedure in patients with intermittent exotropia. Eye 2011;25:449-54.

64. Abroms AD, Mohney BG, Rush DP, et al. Timely surgery in intermittent and constant exotropia for superior sensory outcome. Am J Ophthalmol 2001;131:111-6.

65. Asjes-Tydeman WL, Groenewoud H, van der Wilt GJ. Timing of surgery for primary exotropia in children. Strabismus 2006;14:191-7.

66. Tibrewal S, Singh N, Bhuiyan MI, et al. Factors affecting residual exotropia after two muscle surgery for intermittent exotropia. Int $\mathrm{J}$ Ophthalmol 2017:10:1120-5.

67. Awadein A, Eltanamly RM, Elshazly M. Intermittent exotropia: relation between age and surgical outcome: a change-point analysis. Eye 2014;28:587-93.

68. Yun C-M, Kim S-H. The tendon width of lateral rectus muscle in predicting the effect of recession: is it just age-related artifact? Eye $2011 ; 25: 1356-9$

69. Singh A, Sharma P, Singh D, et al. Evaluation of FD2 (Frisby Davis distance) stereotest in surgical management of intermittent exotropia. Br J Ophthalmol 2013;97:1318-21.

70. Wang J, Hatt SR, O'Connor AR, et al. Final version of the distance Randot Stereotest: normative data, reliability, and validity. J Aapos 2010;14:142-6

71. Holmes JM, Birch EE, Leske DA, et al. New tests of distance stereoacuity and their role in evaluating intermittent exotropia. Ophthalmology 2007;114:1215-20.

72. Stathacopoulos RA, Rosenbaum AL, Zanoni D, et al. Distance stereoacuity. Assessing control in intermittent exotropia. Ophthalmology 1993;100:495-500.

73. Yildirim C, Mutlu FM, Chen Y, et al. Assessment of central and peripheral fusion and near and distance stereoacuity in intermittent exotropic patients before and after strabismus surgery. Am J Ophthalmol 1999;128:222-30.

74. Superstein R, Dean TW, Holmes JM, et al. Relationship among clinical factors in childhood intermittent exotropia. $J$ Aapos 2017;21:268-73.

75. Koklanis K, Georgievski Z. Recurrence of intermittent exotropia: factors associated with surgical outcomes. Strabismus 2009; $17: 37-40$

76. Zou D, Casafina C, Whiteman A, et al. Predictors of surgical success in patients with intermittent exotropia. $J$ Aapos 2017;21:15-18.

77. Gezer A, Sezen F, Nasri N, et al. Factors influencing the outcome of strabismus surgery in patients with exotropia. $J$ Aapos 2004;8:56-60.

78. Hatt SR, Mohney BG, Leske DA, et al. Variability of stereoacuity in intermittent exotropia. Am J Ophthalmol 2008;145:556-61.

79. Adams WE, Leske DA, Hatt SR, et al. Defining real change in measures of stereoacuity. Ophthalmology 2009;116:281-5.

80. Hatt SR, Leske DA, Liebermann L, et al. Variability of angle of deviation measurements in children with intermittent exotropia. $J$ Aapos 2012;16:120-4.

81. Kim WJ, Kim MM. Variability of preoperative measurements in intermittent exotropia and its effect on surgical outcome. J Aapos 2017;21:210-4

82. Yang M, Chen J, Shen T, et al. Clinical characteristics and surgical outcomes in patients with intermittent exotropia: a large sample study in South China. Medicine 2016;95:e2590.

83. Ekdawi NS, Nusz KJ, Diehl NN, et al. Postoperative outcomes in children with intermittent exotropia from a population-based cohort. J Aapos 2009;13:4-7.

84. Romanchuk KG, Dotchin SA, Zurevinsky J. The natural history of surgically untreated intermittent exotropia-looking into the distant future. J Aapos 2006;10:225-31.
85. Kekunnaya R, Chandrasekharan A, Sachdeva V. Management of strabismus in myopes. Middle East Afr J Ophthalmol 2015;22:298-306.

86. Scattergood KD, Brown MH, Guyton DL. Artifacts introduced by spectacle lenses in the measurement of strabismic deviations. Am J Ophthalmol 1983;96:439-48.

87. Hansen VC. Common pitfalls in measuring strabismic patients. Am Orthopt J 1989;39:3-11.

88. Ghali, 2018. Correlation between the axial length and the effect of recession of horizontal rectus muscles. Available: http://www.jeos. eg.net/article.. sp issn=2090-0686; year $=2017$; volume $=110$;issue $=$ 3; spage $=89$; epage $=93$; aulast=Ghali [Accessed 13 Oct 2018] .

89. Pineles SL, Ela-Dalman N, Zvansky AG, et al. Long-term results of the surgical management of intermittent exotropia. $J$ Aapos 2010;14:298-304

90. Yam JCS, Chong GSL, Wu PKW, et al. Predictive factors affecting the short term and long term exodrift in patients with intermittent exotropia after bilateral rectus muscle recession and its effect on surgical outcome. Biomed Res Int 2014;2014:482093:1-4.

91. Pritchard C. Intermittent Exotropia: How Do They "Turn Out"? Am Orthopt J 1993;43:60-6.

92. Kim C, Hwang J-M. 'Largest angle to target' in surgery for intermittent exotropia. Eye 2005;19:637-42.

93. Holmes JM, Hatt SR, Leske DA. Is intermittent exotropia a curable condition? Eye 2015;29:171-6.

94. Raab EL, Parks MM. Recession of the lateral recti. Effect of preoperative fusion and distance-near relationship. Arch Ophthalmol 1975:93:584-6.

95. McNeer KW. Observations on the surgical overcorrection of childhood intermittent exotropia. Am Orthopt J 1987;37:135-50.

96. Ruttum MS. Initial versus subsequent postoperative motor alignment in intermittent exotropia. J Aapos 1997;1:88-91.

97. Pineles SL, Deitz LW, Velez FG. Postoperative outcomes of patients initially overcorrected for intermittent exotropia. J Aapos 2011;15:527-31.

98. Choi J, Kim SJ, Yu YS. Initial postoperative deviation as a predictor of long-term outcome after surgery for intermittent exotropia. $J$ Aapos 2011;15:224-9.

99. Lee S, Lee YC. Relationship between motor alignment at postoperative day 1 and at year 1 after symmetric and asymmetric surgery in intermittent exotropia. Jpn J Ophthalmol 2001;45:167-71.

100. Holmes JM, Leske DA, Hatt SR, et al. Stability of near stereoacuity in childhood intermittent exotropia. J Aapos 2011;15:462-7.

101. Kim H-S, Suh Y-W, Kim SH, et al. Consecutive esotropia in intermittent esotropia patients with immediate postoperative overcorrection more than 17 prism Diopters. Korean J Ophthalmol 2007;21:155-8

102. Moore $\mathrm{S}$. The prognostic value of lateral gaze measurements in intermittent exotropia. Am Orthopt J 1969;19:69-71.

103. Lim HT, Smith DR, Kraft SP, et al. Dissociated vertical deviation in patients with intermittent exotropia. J Aapos 2008;12:390-5.

104. Cho YA, Kim S-H. Surgical outcomes of intermittent exotropia associated with concomitant hypertropia including simulated superior oblique palsy after horizontal muscles surgery only. Eye 2007;21:1489-92.

105. Struck MC, Daley TJ. Resolution of hypertropia with correction of intermittent exotropia. Br J Ophthalmol 2013;97:1322-4.

106. Struck MC, Hariharan L, Kushner BJ, et al. Surgical management of clinically significant hypertropia associated with exotropia. J Aapos 2010;14:216-20.

107. Lee JY, Lee EJ, Park KA, et al. Correlation between the LimbusInsertion distance of the lateral rectus muscle and latera rectus recession surgery in intermittent exotropia. PLoS One 2016;11:e0160263.

108. Kim S-H, Choi Y-J. Effects of unilateral lateral rectus recession according to the tendon width in intermittent exotropia. Eye 2006;20:785-8.

109. Kim S-H, Cho YA, Park C-H, et al. The ultrastructural changes of tendon axonal profiles of medial rectus muscles according to duration in patients with intermittent exotropia. Eye 2008;22:1076-81.

110. Kim S-H, Yi S-T, Cho YA, et al. Ultrastructural study of extraocular muscle tendon axonal profiles in infantile and intermittent exotropia. Acta Ophthalmol Scand 2006;84:182-7.

111. Yao J, Wang X, Ren $\mathrm{H}$, et al. Ultrastructure of medial rectus muscles in patients with intermittent exotropia. Eye 2016;30:146-51.

112. Kim HJ, Choi DG. Consecutive esotropia after surgery for intermittent exotropia: the clinical course and factors associated with the onset. $\mathrm{Br} J$ Ophthalmol 2014;98:871-5. 
113. Kim DW, Han S, Kim US, et al. Results of conservative management for consecutive esotropia after intermittent exotropia surgery. Eye 2015;29:776-82.

114. NCBI, 2018. The surgical management of secondary exotropia. Available: https://www.ncbi.nlm.nih.gov/pubmed/13695307 [Accessed 10 Sep 2018].

115. Chae SH, Chun BY, Kwon JY. The effect of unilateral medial rectus muscle resection in patients with recurrent exotropia. Korean $\mathrm{J}$ Ophthalmol 2008;22:174-7.

116. Ren $\mathrm{M}-\mathrm{Y}$, Wang $\mathrm{T}$, Wang $\mathrm{Q}$, et al. Unilateral medial rectus resection for the treatment of recurrent exotropia in children. Jpn J Ophthalmol 2015;59:341-5.
117. AS-W L, JC-S Y, HH-W L, et al. Surgical outcome of medial rectus resection in recurrent exotropia: a novel surgical formula. $J$ Ophthalmol 2015;2015:758463.

118. Yang HK, Hwang JM. Bilateral vs unilateral medial rectus resection for recurrent exotropia after bilateral lateral rectus recession. Am J Ophthalmol 2009;148:459-65.

119. Kim BH, Suh SY, Kim JH, et al. Surgical dose-effect relationship in single muscle advancement in the treatment of consecutive strabismus. J Pediatr Ophthalmol Strabismus 2014;51:93-9.

120. Kim JY, Lee SJ. Unilateral lateral rectus muscle advancement surgery based on one-fourth of the angle of consecutive esotropia. BMC Ophthalmol 2017;17:266. 